\title{
Effect of the self-management education program on the quality of life in people with chronic heart failure: a randomized controlled trial
}

\author{
Alireza Abbasi ${ }^{1}$, Tahereh Najafi Ghezeljeh ${ }^{2,3}$, Mansoureh Ashghali Farahani ${ }^{4,5}$
}

${ }^{1}$ MSc of Medical-Surgical Nursing, Department of Medical-Surgical Nursing, School of Nursing and Midwifery, Iran University of Medical Sciences, Tehran, Iran

${ }^{2} \mathrm{PhD}$, Associate Professor, Nursing Care Research Center, Iran University of Medical Sciences, Tehran, Iran

${ }^{3}$ Department of Critical Care Nursing, School of Nursing and Midwifery, Iran University of Medical Sciences, Tehran, Iran

${ }^{4}$ Nursing Care Research Center, Iran University of Medical Sciences, Tehran, Iran

${ }^{5} \mathrm{PhD}$, Associate Professor, Department of Medical-Surgical Nursing, School of Nursing and Midwifery, Iran University of Medical Sciences, Tehran, Iran

\section{Type of article: Original}

\begin{abstract}
Background: Chronic Heart Failure (CHF) is a syndrome that negatively affects a person's Quality of Life (QOL). The efficient self-management education program increases the individual's abilities and skills for following and participating in a long-term healthcare plan.

Objective: The aim of this study was to determine the effect of the self-management education program on QOL in people with CHF.

Methods: This randomized controlled trial study was conducted on 60 people with CHF and without sensorycognitive problem from April-August 2015. They were selected using the convenience sampling method, and were randomly assigned into the intervention and control groups. The control group received the routine education presented to participants at discharge. However, besides the routine education, the intervention group received the self-management education program consisting of three sessions followed for a 3-month period. The Iranian heart failure QOL questionnaire was used for data collection before and after the intervention. The independent-samples and paired-samples t-tests, Chi-square and Fisher exact tests were used for data analysis via the SPSS v. 16 software. $\mathrm{P}<0.05$ was considered statistically significant.

Results: No statistically significant differences were reported between the groups in terms of demographic and clinical characteristics, indicating that they were homogeneous. A statistically significant difference was reported between the two groups after the intervention in terms of the mean changes of total QOL $(p<0.001)$ and its dimensions, including symptoms $(\mathrm{p}=0.002)$, social interference $(\mathrm{p}=0.01)$, psychological condition $(\mathrm{p}=0.013)$, and self-efficacy and knowledge $(\mathrm{p}<0.001)$. In addition, an improvement was observed in the total QOL in the intervention group after the education $(\mathrm{p}<0.001)$.

Conclusions: According to the results of this study, the self-management education program can be considered an appropriate strategy for improving the QOL in people suffering from CHF by health care providers.

Trial registration: The trial was registered at the Iranian Registry of Clinical Trials (http://www.irct.ir) with the IRCT ID: IRCT2015032021521N1.

Funding: The authors received financial support for the research, authorship, and/or publication of this article from Iran University of Medical Sciences (No: 107/105/94/D, date April 11, 2015).

Keywords: Chronic, Heart failure, Education, Quality of life, Self-management
\end{abstract}

\section{Corresponding author:}

Associate Professor Dr. Tahereh Najafi Ghezeljeh. Tel: +98.2188882886, Fax: +98.88201978, Email: najafi.t@iums.ac.ir

Received: July 08, 2017, Accepted: May 12, 2018, Published: July 2018

iThenticate screening: May 12, 2018, English editing: July 04, 2018, Quality control: July 12, 2018

This article has been reviewed / commented by four experts

Ethics approval: 94/d/105/107 (Iran University of Medical Sciences)

(C) 2018 The Authors. This is an open access article under the terms of the Creative Commons Attribution-NonCommercialNoDerivs License, which permits use and distribution in any medium, provided the original work is properly cited, the use is non-commercial and no modifications or adaptations are made. 


\section{Introduction}

Chronic heart failure (CHF) is a common condition (1) in which the cardiac output and tissue blood supply are reduced (2). It affects around 26 million people around the world (3). It increases the health care services cause due to resulting in high disability and morbidity. Also, in Asia, CHF is an important health issue, and the range of its prevalence is between $1.3 \%$ and $6.7 \%$ (4). CHF epidemiology has not yet been studied in Iran. CHF is also known as one of the most common causes of long-term hospitalization. Despite advances in the diagnosis and treatment of $\mathrm{CHF}$, about 300,000 deaths occur annually across the world (5). CHF decreases the quality of life (QOL) and leads to the increase of healthcare costs (6). The important target of CHF management is improving QOL, which is indicated by the subjective feelings of people, with regard to the physical, psychological, social, emotional, sexual, and mental well-being in their daily life (7). A study in Iran indicated that a high proportion of women with heart failure had an unfavorable QOL in total, and its dimensions included physical functioning, emotional well-being, mental health, and general health (8). Multiple physical symptoms lead to the disturbance of the person's daily life and may cause mental health disorders. Such problems require the development of a program to manage the person's physical and psychological problems (9). The patient's abilities are important for the implementation of self-management programs, by which a lifestyle modification and the use of therapeutic resources helps improve the symptoms related to CHF (6). Therefore, people with CHF need to be educated about how to monitor and manage the symptoms of CHF (10).

Given the complex nature of CHF, the patient should have sufficient knowledge about medications and diet for monitoring and managing CHF's symptoms. Therefore, there is a need for the development of the person's selfmanagement skills for improving QOL and reducing the incidents of hospitalization $(6,11)$. The aim of the selfmanagement education program is to increase the person's awareness, enhance his/her participation in the management of symptoms and change his/her unhealthy behaviors (12). In fact, the person is responsible for his/her own health and well-being through modifying their lifestyle, and meeting spiritual, physical, emotional and social needs $(13,14)$. The patient is responsible to actively participate in the management and treatment of symptoms (15). $\mathrm{He} /$ she should also identify new symptoms, implement interventions, inform healthcare providers and improve his/her own health information $(16,17)$. The efficient self-management education program increases the individual's abilities and skills for following and participating in the long-term healthcare plan, and reduces the length of hospital stay. The self-management education program may improve self-care and QOL in people with CHF (18, 19). According to a systematic review, a self-management education program on self-efficacy, knowledge improvement regarding nutritional restrictions, health status, exercise, weight loss and proper education helps with peoples' adherence to healthcare interventions and changes their health condition (19). This program can improve the QOL through reducing the mortality rate, length of hospital stay, severity of symptoms (20), treatment costs (21) and physical limitations (22). A few studies have been conducted on the effect of the self-management education program on the QOL in people with CHF (20). Moreover, a systematic review study recommended the need for further studies to assess the effects of a self-management education program on the QOL and mortality rate in people with CHF (23). Therefore, the main aim of this study was to assess the effect of a self-management education program on the QOL in people with CHF.

\section{Material and Methods}

\subsection{Research design and participants}

This randomized controlled trial study was conducted with 60 adult people with CHF from April-August 2015. The research population was hospitalized people with $\mathrm{CHF}$ in a teaching hospital in an urban area of Iran.

\subsection{Selection criteria}

\subsubsection{Inclusion criteria}

The inclusion criteria for the recruitment of the people were as follows: being previously diagnosed with CHF by the physician according to the echocardiography; being stablized in terms of the acute condition of the disease; having no sensory-cognitive problems according to the medical record; being literate and able to speak in Farsi.

\subsubsection{Exclusion criteria}

Any reason for not attending each education session (e.g. discharge from hospital or no desire to continue participating in this study) were considered as exclusion criteria.

\subsection{Sampling}

Given the sample size in the study of Tung et al. (16), a 95\% confidence level, $80 \%$ power, effect size of 7 and $25 \%$ drop-out rate the number of samples was considered as 30 patients in each group. The process of the study was 
shown in Figure 1. There was not any sampling attrition. Participants were selected using the sequential sampling method and were assigned into the intervention and control groups with an equal number of samples in each group with simple randomization method. The participants in the intervention and control groups were selected in different weeks to prevent the contamination of the samples. At the beginning of each week, the first researcher opened a sealed envelope to specify the person's group. It is also noted that the patients in the next group were selected after ensuring that the persons in the other groups were discharged from the hospital.

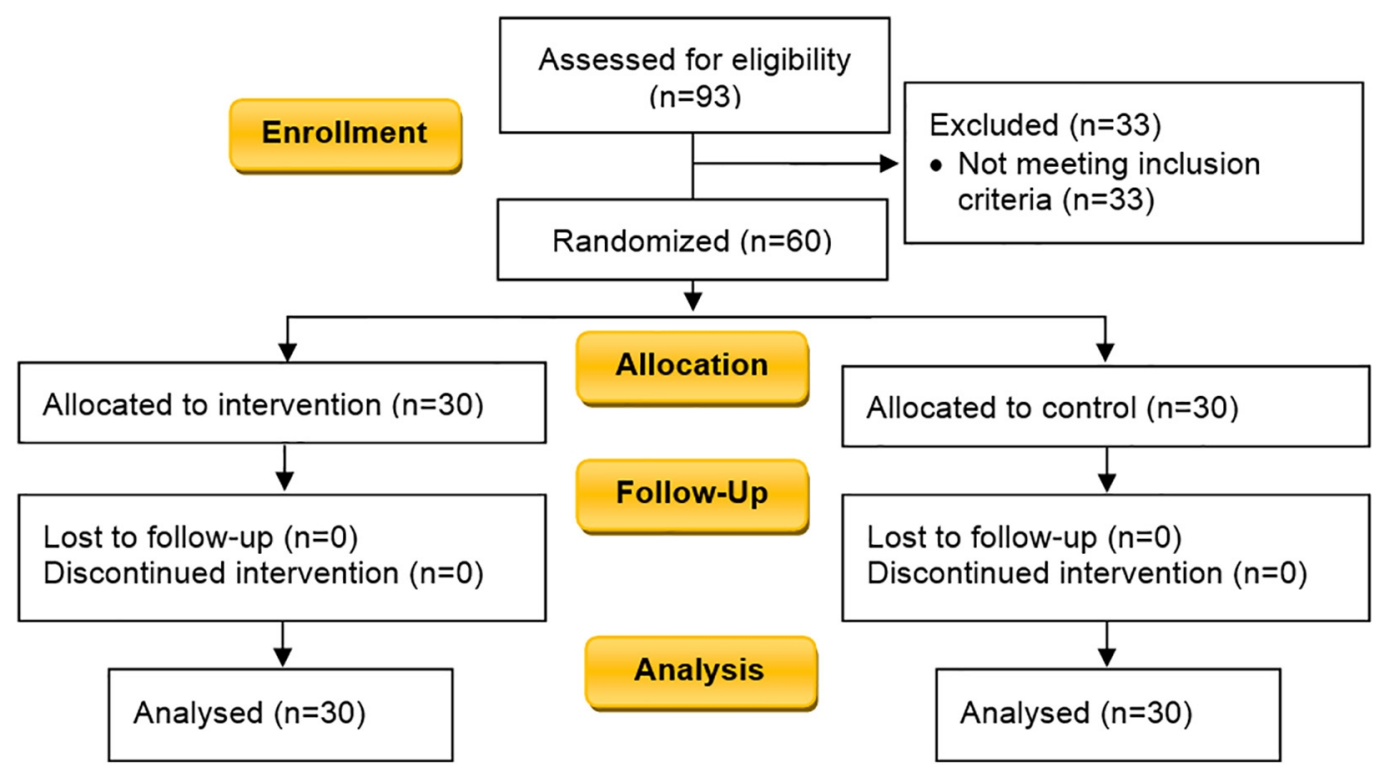

Figure 1. CONSORT 2010 Flow Diagram of the study

\subsection{Intervention and follow-up}

The control group received the routine education presented to patients by an experienced nurse, and an educational pamphlet at discharge. However, besides the routine education, the intervention group received the self-management education program consisting of three sessions followed for a 3-month period. The self-management education program was performed by the first researcher who is an experienced nurse in participants' rooms on three consecutive days. The duration of each session varied between 45 and 60 minutes based on the participants' needs. Furthermore, each session was held individually and education was presented using PowerPoint slides, images, and videoclips. Also, an educational booklet was given to the patients. The self-management education program consisted of information about anatomy and physiology of the heart, CHF's risk factors, symptoms and diagnosis, management of the disease, diet and exercise, medications and their side effects and blood pressure monitoring. This educational content was prepared through literature review and its content validity was confirmed by an expert panel (including two nursing faculty members and one cardiovascular physician). A phone call follow-up was also used for the patients in the intervention group in each month following discharge from the hospital, for ensuring the implementation of what was taught in the sessions. After that data collection was finished, the content of the selfmanagement education program was provided to the participants in the control group.

\subsection{Outcome and instrument}

The primary outcome of this study was QOL. The following questionnaires were used for data collection: the demographic data form and the Iranian heart failure quality of life questionnaire (IHF-QOL). The questions asked in the demographic data form were completed through a review of the patients' medical records or asking questions from the patients before the intervention. In the IHF-QOL 16-item questionnaire (24), questions 1-4 and 6 were for the measurement of the symptoms of the disease and their severity (score 5-20); question 7 was for physical limitations in performing activity (score 5-15); questions 8, 10, 12 and 13 were for social interferences (score 4-12); questions 5, 9 and 11 were for psychological conditions (score 3-10); questions 14 and 15 were for knowledge and self-efficacy (score 2-6) and question 16 was for patient's life satisfaction (score 1-3). The questions were answered using a 3 or 4-point Likert scale. The total QOL score is 15-63 and it was calculated by summing the scores of the questions. The higher scores indicate a higher QOL in total and each dimension. The reliability of the IHF-QOL was determined using the calculation of the intra-class Cronbach's alpha coefficient, which was 0.922 (24). In this study, 
its content validity was confirmed by an expert panel (including 5 nursing faculty members and one cardiovascular physician). The IHF-QOL questionnaire was filled out by the participants of both groups before and three months after the intervention.

\subsection{Data analyses}

The normal distribution of the data was confirmed using the Kolmogorov-Smirnov test. The independent-samples ttest and paired-samples t-test were used for the comparison of quantitative variables between the groups and within groups, respectively. The Chi-square and Fisher exact tests were also applied for the comparison of qualitative variables between the groups. The SPSS software v.16 (SPSS Inc., Chicago, Illinois, USA) was used to analyze data. $\mathrm{P}<0.05$ was considered statistically significant.

\subsection{Ethical considerations}

The ethical committee affiliated with Iran University of Medical Sciences approved this study and corroborated its ethical considerations (Decree No: 94/d/105/107). The trial was registered at the Iranian Registry of Clinical Trials (http://www.irct.ir) with the IRCT ID: IRCT2015032021521N1. A written informed consent form was signed by those participants who willingly agreed to participate in this study. Participation for this study was done voluntarily and each participant could leave the study at any time that they desired without any response. It was guaranteed that there would not be any interruption or flaw in their routine management and there would not be any harm or damage to them.

\section{Results}

The mean age of the patients in the control and intervention groups were 52.30 years $( \pm 15.88)$ and 45.23 years $( \pm 15.93)$, respectively. No statistically significant differences were reported between the groups in terms of demographic and clinical characteristics indicating that they were homogeneous (Table 1).

Table 1. The demographic and clinical characteristics of the patients with CHF in the groups

\begin{tabular}{|c|c|c|c|c|}
\hline \multirow{2}{*}{\multicolumn{2}{|c|}{ Variables }} & \multicolumn{2}{|l|}{ Groups } & \multirow[t]{2}{*}{ p-value } \\
\hline & & Intervention $(\mathrm{n}=30) ; \mathrm{n}(\%)$ & Control $(n=30) ; n(\%)$ & \\
\hline \multirow[t]{2}{*}{ Gender } & Male & $10(33.30)$ & $19(63.30)$ & \multirow[t]{2}{*}{0.08} \\
\hline & Female & $20(66.70)$ & $11(36.70)$ & \\
\hline \multirow[t]{2}{*}{ Marital status } & Single & $10(30.00)$ & $5(16.70)$ & \multirow[t]{2}{*}{0.50} \\
\hline & Married & $20(70.00)$ & $25(83.30)$ & \\
\hline \multirow[t]{3}{*}{ Educational level } & Under diploma & $8(26.70)$ & $16(53.30)$ & \multirow[t]{3}{*}{0.08} \\
\hline & Diploma & $11(36.70)$ & $9(30.00)$ & \\
\hline & Academic degree & $11(36.70)$ & $5(16.70)$ & \\
\hline \multirow[t]{3}{*}{ Income adequacy } & Enough & $8(26.70)$ & $12(40.00)$ & \multirow[t]{3}{*}{0.378} \\
\hline & Somehow enough & $10(46.70)$ & $9(30.00)$ & \\
\hline & Not enough & $8(26.70)$ & $9(30.00)$ & \\
\hline \multirow[t]{3}{*}{ Occupation } & Unemployed & $3(10.00)$ & $3(10.00)$ & \multirow[t]{3}{*}{0.59} \\
\hline & Housewife & $14(46.70)$ & $8(26.70)$ & \\
\hline & Employed & $13(43.30)$ & $19(63.40)$ & \\
\hline \multirow[t]{2}{*}{ Smoking } & Yes & $4(13.30)$ & $3(10.00)$ & \multirow[t]{2}{*}{0.15} \\
\hline & No & $26(86.70)$ & $27(23.30)$ & \\
\hline \multirow[t]{2}{*}{ Exercise } & Yes & $16(53.40)$ & $18(60.00)$ & \multirow[t]{2}{*}{0.79} \\
\hline & No & $14(46.60)$ & $12(40.00)$ & \\
\hline \multirow[t]{2}{*}{ Heart failure classification } & Class I & $16(53.30)$ & $17(56.60)$ & \multirow[t]{2}{*}{0.495} \\
\hline & Class II & $14(46.70)$ & $13(43.40)$ & \\
\hline \multicolumn{2}{|c|}{ Ejection Fraction (Mean \pm SD) } & $28.77 \pm 6.85$ & $30.92 \pm 8.96$ & 0.18 \\
\hline \multicolumn{2}{|l|}{ BMI $\left(\mathrm{kg} / \mathrm{m}^{2}\right)($ Mean \pm SD) } & $26.58 \pm 6.82$ & $27.82 \pm 5.75$ & 0.39 \\
\hline
\end{tabular}

SD: Standard Deviation; CHF: Chronic Heart Failure; BMI: Body Mass Index

The results of the paired t-test showed that no statistically significant differences were found in the control group before and after the intervention in terms of total QOL and its dimensions (Table 2). Furthermore, statistically significant improvements in the scores of the total QOL and its dimensions in the intervention group after the implementation of the self-management education program was reported (Table 2). The comparison of the groups in 
http://www.ephysician.ir

terms of the mean scores of the total QOL and its dimensions before and after the intervention was summarized in Table 2. According to the independent t-test, no statistically significant differences were found in terms of the mean scores of the total QOL and its dimensions, before the intervention. There was a statistically significant increase in the mean change of the scores on the total QOL after the education program in the intervention group compared with the control group (Table 3). In addition, there were statistically significant differences in the mean scores of the changes of symptoms, social interference, psychological condition, and self-efficacy and knowledge between the groups after the intervention. However, no statistically significant differences were reported in the mean scores of the changes of life satisfaction and physical limitations between the groups after the intervention (Table 3 ).

Table 2. The comparison of the mean scores of total QOL and its dimensions between the experimental and control groups before and after the self-management education

\begin{tabular}{|c|c|c|c|c|}
\hline \multirow{2}{*}{ QOL } & \multirow{2}{*}{ Time } & \multicolumn{2}{|l|}{ Groups } & \multirow[t]{2}{*}{$\mathrm{p}$-value } \\
\hline & & $\begin{array}{l}\text { Intervention }(\mathrm{n}=30) \text {; Mean } \\
(\mathrm{SD})\end{array}$ & $\begin{array}{l}\text { Control }(\mathrm{n}=30) ; \text { Mean } \\
\text { (SD) }\end{array}$ & \\
\hline \multirow{3}{*}{$\begin{array}{l}\text { Symptoms and their } \\
\text { severity }\end{array}$} & Before & $11.30(3.13)$ & $12.97(3.41)$ & 0.06 \\
\hline & After & $13.53(3.18)$ & $13.03(3.54)$ & 0.567 \\
\hline & $\mathrm{p}$-value & $<0.001^{*}$ & 0.85 & \\
\hline \multirow[t]{3}{*}{ Physical limitations } & Before & $8.63(1.99)$ & $9.70(2.32)$ & 0.061 \\
\hline & After & $9.50(1.63)$ & $9.87(2.21)$ & 0.468 \\
\hline & $\mathrm{p}$-value & $0.039^{*}$ & 0.517 & \\
\hline \multirow[t]{3}{*}{ Social interference } & Before & $9.66(1.66)$ & $9.40(1.40)$ & 0.506 \\
\hline & After & $10.87(1.17)$ & $9.77(1.57)$ & $0.003^{*}$ \\
\hline & $\mathrm{p}$-value & $<0.001^{*}$ & 0.062 & \\
\hline \multirow{3}{*}{$\begin{array}{l}\text { Psychological } \\
\text { condition }\end{array}$} & Before & $6.43(1.56)$ & $6.30(1.64)$ & 0.749 \\
\hline & After & $7.67(1.42)$ & $6.73(1.25)$ & $0.009^{*}$ \\
\hline & $\mathrm{p}$-value & $<0.001^{*}$ & 0.085 & \\
\hline \multirow{3}{*}{$\begin{array}{l}\text { Self-efficacy and } \\
\text { knowledge }\end{array}$} & Before & $3.20(1.39)$ & $3.53(1.22)$ & 0.33 \\
\hline & After & $4.63(0.99)$ & $3.43(1.07)$ & $<0.001^{*}$ \\
\hline & $\mathrm{p}$-value & $<0.001^{*}$ & 0.522 & \\
\hline \multirow[t]{3}{*}{ Life satisfaction } & Before & $2.60(0.67)$ & $2.37(0.56)$ & 0.15 \\
\hline & After & $2.73(0.52)$ & $2.20(0.71)$ & $0.002 *$ \\
\hline & $\mathrm{p}$-value & 0.326 & 0.231 & \\
\hline \multirow[t]{3}{*}{ Total } & Before & $39.23(5.83)$ & $41.90(7.53)$ & 0.13 \\
\hline & After & $46.20(5.74)$ & $42.83(7.24)$ & 0.051 \\
\hline & $\mathrm{p}$-value & $<0.001^{*}$ & 0.175 & \\
\hline
\end{tabular}

*significant; SD, Standard deviation, QOL, Quality of life

Table 3. The comparison of the mean scores of changes in total QOL and its dimensions between the groups

\begin{tabular}{|l|l|l|l|}
\hline \multirow{2}{*}{ QOL } & \multicolumn{2}{|l|}{ Groups } & \multirow{2}{*}{ p-value } \\
\cline { 2 - 3 } & Experimental $(\mathrm{n}=30)$ & Control $(\mathrm{n}=30)$ & \\
\cline { 2 - 3 } & Mean (SD) & Mean $(\mathrm{SD})$ & \\
\hline Symptoms and their severity & $2.23(3.11)$ & $0.067(1.91)$ & $0.002^{*}$ \\
\hline Physical limitations & $0.87(2.19)$ & $0.167(1.39)$ & 0.145 \\
\hline Social interference & $1.20(1.37)$ & $0.367(1.03)$ & $0.01^{*}$ \\
\hline Psychological condition & $1.23(1.07)$ & $0.43(1.33)$ & $0.013^{*}$ \\
\hline Self-efficacy and knowledge & $1.43(1.43)$ & $-0.10(0.84)$ & $<0.001^{*}$ \\
\hline Life satisfaction & $0.13(0.73)$ & $-0.17(0.75)$ & 0.12 \\
\hline Total & $6.97(6.47)$ & $0.93(3.67)$ & $<0.001^{*}$ \\
\hline
\end{tabular}

*Significant; SD, Standard deviation, QOL, Quality of life.

\section{Discussion}

The aim of this study was to investigate the effect of self-management education on the QOL in people with CHF. In this respect, self-management education improved the scores of the total QOL and most of its dimensions in patients in the intervention group compared with the control group. In addition, the score of the total QOL improved in the 
intervention group after the intervention, compared with the score at the baseline. The self-management education program can further develop the individual's abilities and encourage him/her to follow therapeutic regimes (16). The program can also help patients with CHF to manage their symptoms, increase self-confidence, reduce the length of stay in hospital and improve their QOL (6). Indeed, the self-management education program generally enhances the patient's adherence to the treatment process, resulting in the improvement of the QOL $(25,26)$. Congruous to our study, Smeulders et al. (27) also found that this intervention developed symptoms management, self-care, psychological condition and the QOL in the intervention group compared with the control group. Furthermore, similar studies have shown that self-management education intervention increased self-care behaviors and led to an improvement in the QOL in people with CHF compared with control groups (16). Also, a study by Jonkman et al. (28) indicated that the score of the total QOL significantly improved 6 and 12 months following the selfmanagement education program in people with CHF compared with the control group. However, no significant improvement was reported in the dimensions of the QOL. Moreover, in a study of the self-management education program for patients with chronic diseases, six sessions of education with a duration of 150 minutes were presented. Findings indicated that the QOL significantly increased six months following the intervention in comparison with the control group, demonstrating the effective role of education on the improvement of the QOL (29). A study by Cook and Horrocks (30) showed that the self-management education program enhanced the QOL and self-care behaviors after a three-month intervention in patients with CHF in comparison with the control group. These results are consistent with the results of the current study. According to the findings, self-management education provides information on managing the disease-related conditions, and by utilizing the information, patients may be able to gain control of their condition and therefore, experience an improvement in the QOL. However, in a systematic review of six clinical trials, it was found that the self-management education program reduced the length of hospital stay, the frequency of hospitalization and improved medication adherence in people with CHF. But it had no effect on the mortality rate, functional abilities, symptoms status or QOL (23). The differences can be related to the variations in methodological approach, educational content, education method and following-up periods.

The results of our study indicated that the self-management education program improved symptoms in patients with CHF in comparison with the control group. The study by Wang et al. (31) showed that relief of CHF symptoms such as fatigue could be attained through education delivered by a nurse. These results adhere to the results of the current study. Improvement in the QOL and the reduction of common symptoms of chronic diseases such as sleep problems, require the implementation of the self-management education program (32). Self-management education directs patients in managing symptoms and the precipitating factors of them, which can result in symptom improvements. This study showed that the mean score of the QOL in the dimension of physical limitation was improved; but this difference was not statistically significant compared with the control group. However, the study of McGillion et al. (33) reported that the self-management education program improved the QOL and reduced physical limitations, angina periods and anxiety in people with angina pectoris. Otsu and Moriyama (22), and Smeulders et al. (34) indicated that after the implementation of the 6-month self-management education program, the symptoms of CHF and physical capacities had improved and physical limitations had decreased compared with the control group. Similar results were found in the study by Turner et al. (35) in people with chronic diseases. According to the results of previous studies (22,33-35), changes in physical limitations are achieved with longer time educational programs and six months or more than six months follow up. However, further investigations were recommended. The differences in the results of these studies may stem from different educational protocols, instruments for measuring QOL or methodological limitations such as non-randomization or a low power of the current study. Because symptoms are recurrent in people with CHF, patients are frequently hospitalized, which results in an increase in the cost of treatment and a reduction in social relationships (20). The findings of our study showed the QOL in people with $\mathrm{CHF}$ in the dimension of social interference made a significant improvement following the self-management education program, in comparison to the control group. Another study also reported that the education program ultimately reduced the length of hospital stay and QOL in people with CHF gradually improved (36). Cook and Horrocks (30) stated that after three months, the self-management education program improved the social dimension of the QOL compared with the control group. In the results of study, it can be said that following self-management education and utilizing the related information, patients experience symptom improvement, their re-hospitalization can be decreased and consequently, they can participate in social activities.

The current study showed a significant improvement in the psychological dimension of the QOL in the intervention group compared with the control group. Correspondingly, another study on patients with CHF indicated that the self-management education program led to significant changes in self-care, psychological condition, and the QOL (27). The findings of a study by Musekamp et al. (37) revealed the positive effects of the self-management education 
program in the improvement of the QOL and reduction of depression in people with chronic disorders, following three months of the self-management education program. In the results of study, it can be said that following symptom relief and involvement in social activities, psychological conditions improve. Since individuals are biopsycho-social beings and these dimensions of people are interrelated, every change in a dimension can have an influence on the others. The present study showed that the self-management education program had no effect on the persons' life satisfaction. Life satisfaction as an indicator of the quality of life is related to the evaluation of one's life cognitively. It is related inversely to negative emotions (38) and a high rate of depression is reported in people with CHF (39), which can affect an individual's life satisfaction. In addition, social support plays a key role in the depressive mood and life dissatisfaction in people with CHF (40).

Self-efficacy and knowledge in the intervention group was improved compared with the control group and the baseline, with the implementation of the self-management education program. Correspondingly, the study of Otsu and Moriyama (22), also showed the self-management education program improved self-efficacy and knowledge in people with CHF at three, six, nine and twelve months following the intervention, which, in comparison to the control group led to maintaining the person's health in the long term. Furthermore, results of a study by Liang et al. (41) stated that the self-management education program played a major part in increasing patients' self-efficacy and improving the QOL in cancer patients. Additionally, in a qualitative study by Gholami et al. (42), it was revealed that one of the incentives to seek health information by patients with cardiovascular diseases was to optimize the QOL. In total, it can be said that the basis for the effects of self-management education is increasing patient's knowledge. They learn how to care for themselves and they have confidence in their abilities for successfully handling the disease related situation.

\section{Study limitations}

In the current study, depression and social support were not investigated and therefore, further research is recommended to determine the effect of the self-management education program on depression and social support. Given the limitation of this study, further studies with random allocation and a larger sample size are essential. In addition, more research is necessary to determine the appropriate method for implementing the self-management education program, the duration and method of its follow up.

\section{Conclusions}

People with CHF experience various problems during their illness process that increase the frequency of readmission to hospital. The self-management education program prepares patients to take the responsibility of their own care. Nurses and other healthcare providers consider the self-management education program for improving the QOL in people with CHF. Lifelong adherence to self-management is vital to optimize the treatment outcomes and the disease's prognosis in people with CHF, because of its severity and chronicity. Therefore, the self-management education program with the continuous follow up is essential in health care systems to ensure adherence to the treatment process in patients. According to our findings, the self-management education program can be considered a strategy for improving the QOL, helping to alleviate psychological issues, and improving social and economic conditions in people with CHF. However, more research is necessary to find the appropriate method for improving physical limitations and life satisfaction in people with CHF.

\section{Acknowledgments:}

This article is part of a larger study related to a postgraduate thesis. Researchers appreciate all patients who participated in this study and also staff of the School of Nursing and Midwifery and Shaheed Rajaei Cardiovascular Medical and Research Center, for their assistance in conducting this study.

\section{Trial registration:}

The trial was registered at the Iranian Registry of Clinical Trials (http://www.irct.ir) with the IRCT ID: IRCT2015032021521N1.

\section{Funding:}

The authors received financial support for the research, authorship, and/or publication of this article from Iran University of Medical Sciences (No: 107/105/94/D, date April 11, 2015).

\section{Conflict of Interest:}

There is no conflict of interest to be declared. 


\section{Authors' contributions:}

All authors contributed to this project and article equally. All authors read and approved the final manuscript.

\section{References:}

1) Clark AM, Wiens KS, Banner D, Kryworuchko J, Thirsk L, McLean L, et al. A systematic review of the main mechanisms of heart failure disease management interventions. Heart. 2016; 102(9): 707-11. doi: 10.1136/heartjnl-2015-308551. PMID: 26908100.

2) Matsuoka S, Tsuchihashi-Makaya M, Kayane T, Yamada M, Wakabayashi R, Kato NP, et al. Health literacy is independently associated with self-care behavior in patients with heart failure. Patient Educ Couns. 2016; 99(6): 1026-32. doi: 10.1016/j.pec.2016.01.003. PMID: 26830514.

3) Ponikowski P, Anker SD, AlHabib KF, Cowie MR, Force TL, Hu S, et al. Heart failure: preventing disease and death worldwide. ESC Heart Failure. 2014; 1: 4-25. doi: 10.1002/ehf2.12005. PMID: 28834669.

4) Sakata Y, Shimokawa H. Epidemiology of heart failure in Asia. Circ J. 2013; 77: 2209-17. doi: 10.1253/circj.CJ-13-0971. PMID: 23955345.

5) Scott MC, Winters ME. Congestive Heart Failure. Emerg Med Clin North Am. 2015; 33(3): 553-62. doi: 10.1016/j.emc.2015.04.006.

6) Bingham A, Thompson C, Kell C. A nurse-led initiative to reduce heart failure hospitalizations by improving patient's self-management skills. Heart Lung. 2015; 44(6). doi: 10.1016/j.hrtlng.2015.10.024.

7) Adebayo SO, Olunuga TO, Durodola A, Ogah OS. Quality of life in heart failure: A review. Nig J Cardiol 2017; 14: 1-8. doi: 10.4103/0189-7969.201914.

8) Rahnavard Z, Nodeh ZH, Hatamipour K. Congestive heart failure: Predictors of health-related quality of life in Iranian women. Contemp Nurse. 2014; 47(1-2): 159-67. doi: 10.5172/conu.2014.47.1-2.159. PMID: 25267138 .

9) Currie K, Rideout A, Lindsay G, Harkness K. The association between mild cognitive impairment and selfcare in adults with chronic heart failure: a systematic review and narrative synthesis. J Cardiovasc Nurs. 2011; 30 (5): 382-93. doi: 10.1097/JCN.0000000000000173. PMID: 24988321.

10) Gallagher R. Self management, symptom monitoring and associated factors in people with heart failure living in the community. Eur J Cardiovasc Nurs. 2010; 9(3): 153-60. doi: 10.1016/j.ejcnurse.2009.12.006. PMID: 20093092.

11) Ryan P, Sawin KJ. The individual and family self-management theory: background and perspectives on context, process, and outcomes. Nurs Outlook. 2009; 57(4): 217-25. doi: 10.1016/j.outlook.2008.10.004. PMID: 19631064, PMCID: PMC2908991.

12) Jonkman NH, Westland H, Trappenburg JC, Groenwold RH, Effing-Tijdhof TW, Troosters T, et al. Towards tailoring of self-management for patients with chronic heart failure or chronic obstructive pulmonary disease: a protocol for an individual patient data meta-analysis. BMJ open. 2014; 4(5): e005220. doi: 10.1136/bmjopen-2014-005220.

13) Kenning C, Coventry PA, Gibbons C, Bee P, Fisher L, Bower P. Does patient experience of multimorbidity predict self-management and health outcomes in a prospective study in primary care? Fam Pract. 2015; 32(3): 311-6. doi: 10.1093/fampra/cmv002. PMID: 25715962 PMCID: PMC4445135.

14) Najafi Ghezeljeh T, Yadavar Nikravesh M, Emami A. Coronary heart disease patients transitioning to a normal life: perspectives and stages identified through a grounded theory approach. J Clin Nurs. 2014; 23(3-4): 571-85. doi: 10.1111/jocn.12272.

15) Najafi-Ghezeljeh T, Kassaye Tessama M, Yadavar-Nikravesh M, Ekman I, Emami A. The Iranian version of Angina Pectoris characteristics questionnaire: reliability assessment. J Clin Nurs. 2009; 18(5): 694-9. doi: 10.1111/j.1365-2702.2008.02573.x. PMID: 19239536.

16) Tung HH, Lin CY, Chen KY, Chang CJ, Lin YP, Chou CH. Self-management intervention to improve selfcare and quality of life in heart failure patients. Congest Heart Fail. 2013; 19(4): E9-16. doi: 10.1111/chf.12014. PMID: 23279120.

17) Gaeeni M, Farahani MA, Seyedfatemi N, Mohammadi N. Informational support to family members of intensive care unit patients: the perspectives of families and nurses. Glob J Health Sci. 2014; 7(2): 8-19. doi: 10.5539/gjhs.v7n2p8. PMID: 25716373 PMCID: PMC4796373.

18) Baljani E, Rahimi Z, Heydari S, Azimpour A. The effect of self-management interventions on medication adherence and lifestyle in cardiovascular patients. Scientific Journal of Hamadan Nursing \& Midwifery Faculty. 2012; 20(3): 58-68. 
19) Rezasefat Balesbaneh A, Mirhaghjou N, Jafari Asl M, Kohmanaee S, Kazemnezhad LE, Monfared A. Correlation between self-care and self-efficacy in adolescents with diabetes type 1. Holistic Nursing and Midwifery. 2014; 24(2): 18-24.

20) Ditewig JB, Blok H, Havers J, van Veenendaal H. Effectiveness of self-management interventions on mortality, hospital readmissions, chronic heart failure hospitalization rate and quality of life in patients with chronic heart failure: a systematic review. Patient Educ Couns. 2010; 78(3): 297-315. doi: 21.1016/j.pec.2010.01.016. PMID: 20202778.

21) Do V, Young L, Barnason S, Tran H. Relationships between activation level, knowledge, self-efficacy, and self-management behavior in heart failure patients discharged from rural hospitals. F1000Research. 2015; 4: 150. doi: 10.12688/f1000research.6557.1. PMID: 26213616, PMCID: PMC4505779.

22) Otsu H, Moriyama M. Effectiveness of an educational self-management program for outpatients with chronic heart failure. Jpn J Nurs Sci. 2011; 8(2): 140-52. doi: 10.1111/j.1742-7924.2010.00166.x. PMID: 22117578.

23) Jovicic A, Holroyd-Leduc JM, Straus SE. Effects of self-management intervention on health outcomes of patients with heart failure: a systematic review of randomized controlled trials. BMC cardiovascular disorders. 2006; 6: 43. doi: 10.1186/1471-2261-6-43.

24) Naderi N, Bakhshandeh H, Amin A, Taghavi S, Dadashi M, Maleki M. Development and Validation of the First Iranian Questionnaire to Assess Quality of Life in Patients With Heart Failure: IHF-QoL. Res Cardiocvasc Med. 2012; 1(1): 10-6. doi: 10.5812/cardiovascmed.4186. PMID: 25478482, PMCID: PMC4253883.

25) Buck HG, Lee CS, Moser D, Albert NM, Lennie T, Bentley B, et al. Relationship between self-care and health-related quality of life in older adults with moderate to advanced heart failure. J Cardiovasc Nurs. 2012; 27(1): 8-15. doi: 10.1097/JCN.0b013e3182106299. PMID: 21558868.

26) Cockayne S, Pattenden J, Worthy G, Richardson G, Lewin R. Nurse facilitated self-management support for people with heart failure and their family carers (SEMAPHFOR): a randomised controlled trial. Int J Nurs Stud. 2014; 51(9): 1207-13. doi: 10.1016/j.ijnurstu.2014.01.010. PMID: 24508285.

27) Smeulders ES, van Haastregt JC, Ambergen T, Uszko-Lencer NH, Janssen-Boyne JJ, Gorgels AP, et al. Nurse-led self-management group programme for patients with congestive heart failure: randomized controlled trial. J Adv Nurs. 2010; 66(7): 1487-99. doi: 10.1111/j.1365-2648.2010.05318.x. PMID: 20492026.

28) Jonkman NH, Westland H, Groenwold RH, Agren S, Atienza F, Blue L, et al. Do self-Management interventions work in patients with heart failure? An individual patient data meta-analysis. Circulation. 2016; 133(12): 1189-98. doi: 10.1161/CIRCULATIONAHA.115.018006. PMID: 26873943, PMCID: PMC5180429.

29) Smith ML, Cho J, Salazar CI, Ory MG. Changes in quality of life indicators among Chronic Disease SelfManagement Program participants: an examination by race and ethnicity. Ethn Dis. 2013; 23(2): 182-8. PMID: 23530299.

30) Cook J, Horrocks S. Evaluation of a heart failure self-management programme. BJCN. 2015; 10(12): 6038. doi: 10.12968/bjca.2015.10.12.603.

31) Wang TC, Huang JL, Ho WC, Chiou AF. Effects of a supportive educational nursing care programme on fatigue and quality of life in patients with heart failure: a randomised controlled trial. Eur J Cardiovasc Nurs. 2016; 15(2): 157-67. doi: 10.1177/1474515115618567. PMID: 26585292.

32) Ory MG, Smith ML, Ahn S, Jiang L, Lorig K, Whitelaw N. National study of chronic disease selfmanagement: age comparison of outcome findings. Health Educ Behav. 2014; 41(1 Suppl): 34S-42. doi: 10.1177/1090198114543008. PMID: 25274709.

33) McGillion M, O'Keefe-McCarthy S, Carroll SL, Victor JC, Cosman T, Cook A, et al. Impact of selfmanagement interventions on stable angina symptoms and health-related quality of life: a meta-analysis. BMC cardiovascular disorders. 2014; 14: 14. doi: 10.1186/1471-2261-14-14. PMID: 24483947, PMCID: PMC3945741.

34) Smeulders ES, van Haastregt JC, Ambergen T, Janssen-Boyne JJ, van Eijk JT, Kempen GI. The impact of a self-management group programme on health behaviour and healthcare utilization among congestive heart failure patients. Eur J Heart Fail. 2009; 11(6): 609-16. doi: 10.1093/eurjhf/hfp047. PMID: 19359326.

35) Turner A, Anderson JK, Wallace LM, Bourne C. An evaluation of a self-management program for patients with long-term conditions. Patient Educ Couns. 2015; 98(2): 213-9. doi: 10.1016/j.pec.2014.08.022. PMID: 25441096. 
36) Baker DW, DeWalt DA, Schillinger D, Hawk V, Ruo B, Bibbins-Domingo K, et al. "Teach to goal": theory and design principles of an intervention to improve heart failure self-management skills of patients with low health literacy. J Health Commun. 2011; 16(3): 73-88. doi: 10.1080/10810730.2011.604379. PMID: 21951244.

37) Musekamp G, Bengel J, Schuler M, Faller H. Improved self-management skills predict improvements in quality of life and depression in patients with chronic disorders. Patient Educ Couns. 2016; 99(8): 1355-61. doi: 10.1016/j.pec.2016.03.022. PMID: 27050107.

38) Kuppens P, Realo A, Diener E. The role of positive and negative emotions in life satisfaction judgment across nations. Pers Soc Psychol. 2008; 95(1): 66-75. doi: 10.1037/0022-3514.95.1.66. PMID: 18605852.

39) Allman E, Berry D, Nasir L. Depression and coping in heart failure patients: a review of the literature. J Cardiovasc Nurs. 2009; 24(2): 106-17. doi: 10.1097/JCN.0b013e318197a985. PMID: 19242276.

40) Perez-Garcia AM, Olivan S, Bover R. Life satisfaction, depressive symptoms and perceived social support in heart failure patients. Revista de Psicopatología y Psicología Clínica 2013; 18(2): 93-105. doi: 10.1002/smi.1378.

41) Liang SY, Chao TC, Tseng LM, Tsay SL, Lin KC, Tung HH. Symptom-management self-efficacy mediates the effects of symptom distress on the quality of life among Taiwanese oncology outpatients with breast cancer. Cancer Nurs. 2016; 39(1): 67-73. doi: 10.1097/NCC.0000000000000244. PMID: 25730592.

42) Gholami M, Fallahi Khoshknab M, Khankeh HR, Ahmadi F, Maddah SS, Mousavi Arfaa N. The motivations of Iranian patients with cardiovascular disease to seek health information: a qualitative study. Iran Red Crescent Med J. 2016; 18(5): e26039. doi: 10.5812/ircmj.26039. PMID: 27437128, PMCID: PMC4939227. 